\title{
LA DESTRUCCIÓN HEIDEGGERIANA DE LA METAFÍSICA DEL COGITO
}

En buena medida, el siglo $\mathrm{xx}$ ha estado polarizado filosóficamente en Descartes, al menos en dos corrientes capitales, la Fenomenologia y la Hermenéutica, que han constituido un eje central de la reflexión filosófica contemporánea. Esto no significa, sin embargo, que haya sido un siglo "cartesiano", en sentido escolástico. Más bien cabria inferir lo contrario, pues en la medida en que un autor se convierte en centro de debate e interpretación, deja de ser tradición inerte para volverse radicalmente problemático y vivo. Esta ha sido, a mi juicio, la suerte de Descartes en este siglo. No hay problema vivo de la filosofia de hoy, en cuyo trasfondo no aparezca.' Pero, fundamentalmente, los avatares del cartesianismo, o lo que podríamos llamar la historia interna de sus vicisitudes en el pensamiento contemporíneo ha estado vinculada intimamente a la crisis de la Fenomenolo-gía. Si el giro transcendentalista de la obra de Husserl, a partir de ldeas I, significó un renacimiento del estilo cartesiano, era de esperar que la disidencia interna provocada por este viraje supusiera una profunda revisión del cartesianismo. La distancia entre estos planteamientos salta a la vista si se compara Mléditations cartésiennes de Husserl, con su expresa intención reactualizadora, con Sein und Zeit de Heidegger, programáticamente destructor. Al comienzo de sus conferencias en la Sorbona, Husserl reconoce explicitamente su deuda con Descartes:

Por el estudio de sus Meditaciones la naciente fenomenologia se ha iransformado en un tipo nuevo de filosofia transcendental. Se podria llamar casi un neo-cartesianismo...2

Y para evitar cualquier sentido meramente restauracionista o arcaizante de su tarea, precisa al final de su Introducción:

\begin{abstract}
¿No consistiria el único renacimiento verdaderanente fecundo en resucitar las Meditaciones cartesianas, no ciertamente para adoptarlas integramente, sino para desvelar la significación prolunda de un retomo radical al ego cogito puro y hacer revivir luego los valorts ctermos que de alli surgen??. Este es. al menos, el camino que ha conducido a la fenomenologia transcendental.3
\end{abstract}

Si se tiene en cuenta que estas conferencias fueron pronunciadas en 1929, dos anos después de la publicación de Ser y tiempo, es fäcil ver en la reivindicación husserliana de Descartes una réplica a la incipiente destrucción del cartesianismo, que se estaba provocando en los circulos fenomenológicos disidentes. Y reciprocamente, suena a contrarréplica expresa a llusserl, la advertencia heideggeriana, años más tarde, de que la vuelta al cartesianismo no era más que una insistencia en lo ya consumado. "Con Descartes conienza la consumación (lollending) de la metafisica occidental" (1Iw, 91). Con él no puede comen-

1 La recuperación del cuerpo o la carne, frente a la tradición platónico/eartesiana, el replantearniento de la relación cterpo/mente, el problema del otro, la crisis de la razón, el debate en torno a la epistemologia como discurso conmensurable, el carácter natural o bien instrumental del lenguaje constitusen un amplio elenco de temas, que obligan, en última instancia, a adoptar una postura determinada con respecto al cartesianismo.

2 Méfitations cortisiemes. Introduction a la Pleinomenologie, Vrin, Paris, 1969. pág 1.

3 Idem, 5

4 "Die Zejt des Weltbldes" (1938), recogido en Holzwege (llw), Klostermann, Franckfurt, 1950. 
zar nada nuevo, que esté en condiciones de afrontar los problemas de la era cientifico/técnica, porque ésta no es más que la realización consecuente del proyecto cartesiano de la mathesis tuniversalis.

He partido de estas dos grandes obras para presentar el conflicto enre Husserl y Heidegger en su punto más álgido de tensión. Pero sus diferencias en torno al cartesianismo vienen de antes, desde el comienzo de los años veinte, en el mismo origen del pensamiento heideggeriano, polarizado en contra de la lectura apropiadora que Husserl venia haciendo de Descartes. Como ha señalado Jean-Luc Marion, "Descartes, tal como lo encuentra Heidegger, tiene ya estatuto de motivo fenomenológico, si no rango de fenomenólogo. Descartes aparece en primer lugar, para Heidegger, positivamente como fenomenólogo a partir de Husserl". 5 En efecto, desde las Conferencias de Göttingen, en 1907, Husserl venía presentando la Fenomenologia como una recuperación consecuente del gesto fundacional del cartesianismo. Esto suponia tanto que la Egolología husserliana se entendia a si misma como un desarrollo de la epistemologia cartesiana en dirección trascendentalista, como, en sentido inverso, que el trascendentalismo de Husserl se amparaba en la tesis metafisica de la autoconciencia en Descartes. Tal como plantea certeramente la cuestión J.L. Marion, "o bien Descartes es fenomenólogo porque anticipa a Husserl, o bien, la fenomenologia husserliana no es enteramente fenomenológica, porque permanece prisionera de decisiones cartesianas no criticadas". Una temprana controntación con la obra de Descartes lleva a Heidedegger a descartar la primera posibilidad en favor de la segunda. Eil ego cogito podia aparecer asi como la prima veritas ontológica, y en este sentido, la Fenomenologia constituia una tesis fuerte metafisica, convirtiendo la fundamentalidad trascendental de la conciencia en una primordialidad ontológica. Estc es precisamente el punto en que inciden las primeras criticas de Heidegger, desde el inicio de los anos veinte, al cartesianismo. Descartes no la analizado el modo de ser propio del ego, limitándose a doblar un planteamiento epistemológico con una interpretación metafisica sustancialista. Asumir a Descartes, como venia haciendo Husserl, equivalía, pues, a marrar el mismo proyecto fenomenológico. En definitiva, "Descartes surge asi como el motivo no fenomenológico de llusserl", ${ }^{6} 0$ dicho a la inversa, Husserl se ensombrece, fenomenológicamente hablando, con el motivo metafisico cartesiano. Si se añade a esta plantcamiento metodológico, una intención estratégica, podia asegurarse, sin pecar de insidjoso, que Descartes le sirve a Heidegger para un ajuste de cuentas con Husserl, a la vez que Husserl le permite ponderar en su real envergadura histórico/ontológica el descubrimiento cartesiano.

A esta luz, el programa heideggeriano de destrucción del cartesianismo, emprendido ya de modo consecuente desde Sein und Zeit, no puede por menos de ser considerado como un ataque dirigido al núcleo mismo de la Egología lusserliana, en aras de una mayor fidelidad a la exigencia fenomenológica de "ir a las cosas mismas". Pero no agota en ésto sus alcanç. El propósito de Heidegger significaba históricamente una revisión completa de la modernidad. Más allá, pues, de un debate interno en torno a la posición hibrida, a la que podriamos denominar convencionalmente husserliano/cartesiana, se trataba de un encuestamiento radical de las premisas fundacionales de la época moderna. A partir de este planteamiento se comprende que el intento heideggeriano de cuestionamiento y superación de la modernidad haya estado forzosamente polarizado en el cartesianismo. Si Hussert representa una estilización en senti-

5 Jeas-Lue Marion, Rédıction et donation (Recherches sur Hhsserl, Heidegger et la phénoménologie), PUF, Paris, 1989, pag 124.

6 Ibidem. 
do transcendental de la metafisica del cogito, Heidegger, en contrapartida, significa la destranscendentalización y superación del principio cartesiano de la conciencia, y, por tanto, de la misma Egologia trascendental de su maestro Husserl. O, por decirlo en los términos metafisicos, mientras Husserl permanece dentro de los limites constitutivos de la inmanencia cartesiana, Heidegger los ha traspasado hacia la trascendencia. Descartes se ha convertido asi en una encrucijada decisiva. El debate en torno al dilema idealismo-realismo, que prosperó al principio del siglo, la fenomenologia existencial o mundana, la lermenéutica de la facticidad histórica, la problemática de la crisis de la llustración y el inicio de los planteamientos de la postmodernidad son buena prueba de ello. En este contexto histórico, agudizado por una conciencia de extenuación de la gran filosofia, caracteristica de estas postrimerias del siglo, quisiera revisar hoy el episodio filosófico fundamental de esta historia: la destrucción heideggeriana de la metafísica del cogiro.

A modo de obertura, anticipo ya mi tesis al respecto: la superación del cartesianismo no es una mera consecuencia del planteamiento de Hejdegger, sino su tarea interna fundamental, hasta el punto de que su filosofia resulta incomprensible al margen de esta destrucción. Se diria que el adversario de Heidegger, no es Kant, ni siquiera Hegel, sino Descartes, como trasfondo último determinante del trascendentalismo de Husstrl. En esta tarea, Heidegger ha realizado dos lecturas critico/ superadoras de Descartes, que vienen a corresponderse puntualmente con las etapas internas de su obra, -el primer y el segundo Heidegger-, y que estản, por tanto, demarcadas y, a la vez, conexas por el tema de la "vuelta" o "viraje" (Kelhre). Estas lecturas son complementarias, pero, no obstante, difieren entre si, a modo de tiguras simétricas incongruentes, pues la segunda y definitiva no coincide ni es superponible a la primera, en la medida en que logra poner a ésta a una nueva luz, la reitera y conjuntamente cava más hondo su propio surco, y con ello le hace franquear delinilvamente el espacio de la modernidad, abierto por las Meditationes de prima philosofia cartesianas. Podria formularse en otros términos: la primera lectura explora lo impensado por Descartes, -el sum del cogito- mientras que la segunda se atiene a lo que Descartes ha pensado explicitamente acerca del ego cogito como principio o fundamentun inconcussum veritatis. $Y$ otro tanto vale con respecto a Husserl, que si en la primera lectura es socavado en su trascendentalismo en virtud de la misma exigencia fenomenológica, en la segunda queda realmente jurgado y superado como el pensador que consuma la modernidad cartesiana. En lo que sigue voy a limitarme a esbozar la linea directriz del proyecto heideggeriano de destrucción del cartesianismo.

\section{El programa de una destrucción de la metafisica}

Como se sabe, la critica a Descartes se inscribe en la tarea heideggeriana, formulada en Sein und Zeit de destruir la historia de la ontologia occidental. Pese a la evocación apocaliptica del término, la destrucción (Destruktion) no es más que un replanteamiento de la historia de la metafĩsica, a la luz de la nueva pregunta por el sentido del ser. Pero en la medida elt que esta pregunta, en cuanto histórica, está lä́cticamente determinada, se ve obligada a traer a la luz la listoricidad a que pertenece y encarar, por tanto, la tradición. En virtud precisamente del carácter irreflexivo e ingenuo, ésto es, dogmático, en que se está en la tradición, ésta suele pasar desapercibida, o bien le confiere a sus contenidos la apariencia de lo incuestionable:

La tradición que asi viene a imperar, hace inmediata y regulamente lo que transmite tan pocu accesible que unás bien lo eneubre. Considera lo tradicional como comprensible de sujo y obstruye el acce. 
so a las fientes originales de que se bebieron, por modo genuino en parte, los conceptos y categorias transmitidos. La tradición llega a hacer olvidar totalmente tal origen (SZ, pr. 6), ${ }^{7}$

Mas la pregunta, si es en verdad cuestionante de modo genuino, tiene que perforar ustas capas encubridoras y poner a la luz "Ias experiencias originales" (die ursprïnglichen Erfalorungen), para que puedan manar de nuevo. En una palabra, tiene que tras-pasar la tradición, pasar a su través, y superarla, no en el sentido de dejarla atrás transcendida al modo hegeliano (aufhehoben), sino de sobre-ponerse a y reponerse de ella (übernunden), poniendo las cosas en su sitio, es decir, en el lugar (Orf) originario de su aparición. La destruccion, pues, no tiene un sentido negativo, al modo relativista o escéptico, sino básicamente positivo, re-descubridor. Propiamente lablando, es una vuelta rememorativa a los origenes con vistas a una "apropiación positiva del pasado" (in der posisiven dneignung der lérgangenheit). Y mediante esta apropiación, a la par que se ilumina el horizonte del presente, en su real gestación y acontecer, se confirma o verifica en concreto la pregunta hermenéutica directiva en su capacidad para despejar un nuevo ámbito de clarificación. De ahi que esta tarea no pertenezca a la historia doxográfica (Historie), sino a la historia/acontecimento (Geschichte), o, por decirlo con el último Heidegger, al acaecer mismo destinal del ser (Geschick). Inevitablemente esta tarea se encuentra limitada en su alcance por su misma facticidad histórica. Como precisa Heidegger, "debe, a la inversa, acotarla (= la tradición) dentro de sus posibilidades positivas, y esto quiere decir siempre dentro de sus límites (in ihren Grenzen), que le están dados fácticamente con el modo de hacer la pregunta" (SZ, pr. 6). ${ }^{8} \mathrm{Y}$ en la medida en que la pregunta heideggeriana se interroga originariamente por el sentido del ser, es decir, no simplemente por qué es el ente, sino por cómo aparece o se muestra en cuanto tal ente conforme al modo temporal de esta aparición, - isto es lo que indica la conjunción ser y tiempo-, está en condiciones de llevar a cabo una encuestación radical de la historia ontológica en función del modo mismo del aparecer o advenir histórico del ser. Es, pues, la anticipación de la "diferencia ontológica", envuelta en la propia pregunta heideggeriana por el sentido del ser, la que le permite discernir y sacar a luz dimensiones de la tradición ontológica, en las que ha quedado sepultada la diferencia. Puede, por tanto, denunciar las latencias u olvidos, que obran en la historia de la metafisica por encubrimiento de esta pregunta radical.

En esta historia, la estación cartesiana ocupa para Heidegger un puesto central. Es realmente un punto crucial de recepción y de inflexión. De un lado, Descartes, aplica sin cuestionarlo las categorias ontológicas, transmitidas por el medioevo, a su nuevo punto de partida en la autoconciencia, interpretándolo a la luz de la metafisica griega de la ousia (parousia) o sustancia; pero, a la vez, modifica o inflexiona decisivamente lo transmitido, haciendo emerger la categoria fundante del sujeto. Descartes representa, por tanto, en la historia ontológica, el punto de viraje de la sustanticialidad del ser a la subjetividad. $Y$ en tanto que éste es el principio del nuevo tiempo, por ser el modo en que se formula de nuevo la cuestión del fundamento, la posición cartesiana resulta responsable del curso posterior de la modernidad (Leibniz, Kant, Hegel) hasta su consumación en la metafisica nietzscleana de la "voluntad de poder", $y$-cabría añadir, cosa que explicitamemte no dijo, que yo sepa, Heidegger- en la Egologia husserliana. En Descartes, pues, tiene que estar latente la ocultación originaria de la pregunta ontológica por el

7 Sein sud Zeir, Max Niemeyer, Halle, 1941, pág. 21; trad. esp. de José Gaos, El ser y el tiempo, FCE, México,1951, pág. 31.

$8 \mathrm{SZ}, 22 ; \mathrm{ST}, 33$. 
sentido del ser, y con ello, el olvido más radical y extremo de la "diferencia ontológica" en una cultura antropológico/humanista. De ahí que Descartes sólo pueda ser superado

a través de la superación de aquello que él mismo ha fundado, a través de la superación de la metafisica modema, y, conjuntamente de la melafisica occidental (Hw, 92),

es decir, por un planteamiento capaz de cuestionar desde su origen lasta su consumación la metafisica de la subjetividad. La destrucción de la metafisica del cogito significa, pues, desmontar desde dentro el principio cartesiano de la autoconciencia, y en su lugar, esto es, en el lugar del fundamento, no poner un ente determinado y privilegiado, sino el extático acontecer (Ereignis) de la verdad del ser.

Lo peculiar de Descartes es que el olvido de la pregunta por el ser se hace en él más tlagrante que en ningún otra estación ontológica. Esta omisión se habria producido, según Heidegger, en el mismo punto de partida:

"Con el cogito simm pretende Descartes dar a la filosofia una base nueva y segura. Pero lo que at deja indeterminado en este comienzo radical es la forma del ser de la res cogitans, o mós exactannente, el sentido del ser del stm" (SZ, pr. 6).9

Pese a que en la formulación del principio mantiene Descartes el enlace de los dos radicales: el sum y el cogiro, en vez de atenerse al nudo de esta relación, presta su atención cxclusivamente a la cogitatio, pasando por alto la naturaleza del sum. La deja, pues, sin dilucidar iA qué atribuir - cabe preguntarse - semejante actitud?. Podria pensarse que Descartes no la analiza porque la da por supuesta, esto es, la toma de modo inmediato de la tradición metafísica medieval. Más que dejarlo indeterminado (unbestimmt) ${ }^{10}$ habría que decir que lo da por sentado. Establecido, a través de la duda, el caráter indubitable del cogito, como aquel acto que subsiste o prevalece en cualquier intento de su negación. Descartes creyó necesario admitir un sujeto del acto como el supósito (hypokeimenon), donde reside tal operación, y por tanto, a sustantivar el sum. El cogito presupone una res cogitans, esto es, una sustancia, cuya naturaleza o atributo esencial es pensamiento. Estrepitosamente se viene abajo en este punto toda la precaución cartesiana en torno a las ideas recibidas, pues deja que se le cuele por su aduana nada menos que la categoria central del pensamiento ontológico: el sentido del ser como sustancia. Descantes habria arrastrado asi -cree Heidegger- un "pre-juicio fatal" (SZ, pr.6)." Paradójicamente, podría sospecharse que Descartes olvida esta cuestión en virtud de su propio radicalismo, porque al desconectar metódicamente de la tradición recibida en búsqueda de una experiencia originaria, de la que pudiera dar cuenta por si mismo, creyó ingenuamente ponerse a buen recaudo de toda influencia de esa tradición, sin apercibirse de que dejaba sin revisar, intactas, sus propias categorias ontológicas. La creencia ahistórica en la posibilidad de un comienzo absoluto lo dejó paradójcamente desarmado ante la terca y soterrada presencia

9 SZ, 24 y ST,34-5. Véase tambien SZ,46 y ST,58.

I0 Jean-Luc Marion ha rechazado con muy solidos argumentos que Descartes dejara indetenminado, ct el sentido de no-tematizado, el sum del cogito, puesto que reintrepeta a su luz en un sentido egologico la categoria de sustancia (Sur le prisme mécoplýsique de Descartes, PUF, Paris, 1986, págs 177-80). Creo que en todo ésto lay un equivoco. Heidegger no puede negar lo obvio, a saber, que Descartes interpreta el sum como sustancia (res cogitans), sino que mús bien, por dar por sentado que es una sustancia, deja encubierto, no dilucidado, el sentido ex-sistenial del stmin.

I) $\mathrm{SZ}, 25 ; \mathrm{ST}, 35$. 
en la historia del peso de la tradición. Esta es, esquemátiamente expuesta, la linea argumental con que la Hermenéutica gadameriana se enfrenta a la pretensión ilustrada de un comienzo absoluto.

Pero hay otras posibles respuestas complementarias. Cabe pensar también con Heidegger que "con el absoluto ser cierto (Gewisssein) del cogito, se sintió Descartes dispensado de interrogarse por el sentido del ser de este ser" (SZ, pr. 6). 12 Fué, pues, la misma evidencia con que se le impuso a Descartes el factum de la cogitatio, la que le impidió problematizar el sentido de su ser. ${ }^{13}$ No es dificil reconstruir la línea por la que Descartes llegó a la identiticación del yo soy con un subiectum sustancial. El lugar originario de todo "darse cuenta" no puede no ser, pues tiene la prueba de la irrefutabilidad de su acto. Todo intento de negarlo o de ponerlo entre paréntesis, mediante la duda metódica, lo hace aparecer, pues si dudo, incluso si dudo que dudo, pienso puesto que dudo. Por tanto, el acto es, $y$ es en su propio darse cuenta o auto-aparecerse: es pensamiento. Alora bien, dado que esta presencia o constancia de lo presente/permanente era lo mentado por la categoria griega de la ousía (= sustancia en latín por una pésima traducción), tal acto no puede menos de ser una realidad sustancial. Esta línea de argumentación cartesiana parece subyacer a su respuesta a la objeción de Hobbes. Cuando éste le reprocha que es preciso distinguir entre el acto y su sujeto, y preguntarse si la naturaleza del sujeto es otra que la cogitatio, por ejemplo, el cuerpo, y si es éste el verdadero soporte, como más tarde argüirá de nuevo Nietzsche contra Descartes, éste le contesta que es tal la claridad con que percibe la naturaleza del pensaniento y su distinción de la idea de cuerpo o extensión, que no puede admitirlos como caracteres de una misma sustancia. Sienta asi, a mi juicio, el principio ontológico determinante de todo el idealismo metafísico: lo que se concibe clara y distintamente ha de existir separadamente en la realidad. Por tanto, el modo de aparecer es determinante de la distincion real de lo que aparece. Y puesto que el cogito consiste en auto-aparecerse, en ser pura autopresencia, tiene que existir separadamente como sustancia.

Por eso, no tiene sentido, a mi juicio, la objeción que le hace Hobbes, y que se reiterará mas tarde contra la Fenomenología, de que es imposible pensar que se piensa, dado que todo pensamiento es sobre otro pensamiento anterior. Pensar que se piensa no es aquí, propiamente hablando, una reflexión, sino la autotransparencia del acto de pensar a si mismo, de modo que todo pensar algo es conjuntamente co-apercibirse o darse cuenta de estar pensando, y por tanto, autopresencia del acto pensante a si mismo. Esto es justamene lo que significa "cogitatio","tout ce qui se fait en nous de telle sorte que nous l'apercevons inmmediatement par nous mêmes"(Princ., 9), ${ }^{14}$ ésto es, lo que se da por modo inmediato unido a la conciencia de si mismo; $y$, por tanto, de modo radical y propio, aquellas cogitaciones que brotan internamente de si mismo, o de la pura luz natural de la razón. De ahi que pensar implique un sujeto. No sa en la misma medida en que cualquier acto reclama un supuesto ontológico donde radicarse, sino en la más radical y propia de que el acto de pensar (cogitatio) es saberse presente a sí. Descartes no dice la platitude de que pienso y por tanto soy ya que no pueda darse un acto carente de sujeto real, sino que sólo en el acto de pensamiento, en cuanto auto-aparición, está dada la evidencia de su sujeto, como presente y manifiesto en si. Por eso no se trata de una con-

$12 \mathrm{SZ}, 24 ; \mathrm{ST}, 35$.

13 Vease a este respecto P. Ricoeur, "Heidegger et la question su sujet", en Le con/it des interprétations, Du Seuil, Paris, 1969, págs 226-7.

14 Les principes de la philosophie (PF) en Descartes, Oentes et Lettres, Gallitnard, Paris, 1953, pajg 574. 
clusión lógica, como parece obvio, sino de una intuición o manifestación. "Je pentse donc je suis. Combien de temps?) —se pregunta Descartes. "A savoir, autant de temps que je pense"(Med.,2). ${ }^{15}$ Esta referencia al tiempo es muy significativa. En puridad cartesiana, hay que afirmar que se existe en tanto que se piensa; que la existencia del yo sólo está asegurada a la vez que acontece y en tanto que acontece el acto de pensamiento. Por tanto, que se da en el presente absoluto de la autopresencia inmediata del pensamiento a si mismo. Era fácil, pues, la transición a que este sujeto de actos, presente en ellos, es lo permanente e idéntico en su ser, esto es, una sustancia. Así piensa Descartes, ateniéndose, según Nietzsche, a la Lógica de un "hábito gramatical, que la acción atribuye un actor", 16 y que ha determinado la creencia en la existencia de un yo. Si el ego del ego sum es sujeto, su sum no puede ser más que sustancia. Lo correspondiente ontológicamente a un centro y fundamento de actos seria la permanencia de una naturaleza pensante, llámese mens, espíritu, entendimiento o razón (Med., 2). ${ }^{17}$ "Se produce asi —advierte P. Ricoeur - una suerte de complicidad, de identificación entre las dos nociones de subiectum como fundamento y de subiectum como yo".18 Más tarde Kant denunciará, como se sabe, - y a partir de él será ya moneda corriente - el paralogismo transcendental de tomar un sujeto lógico de constitución por un sujeto ontológico de inhesión, o dicho de otro, la unidad de la autoapercepción de la conciencia, que acompaña de modo nesesario a sus representaciones, por la unidad de un supuesto sustancial. Pero el equivoco está montado en la duplicidad misma de la presencia, como lo presente a si mismo, en la intimidad o iumediatez de su acto, y lo presente/permanente bajo el flujo de sus modificaciones. Sin duda, Descartes fué víctima de este espejismo. Fué, pues, la evidencia o la certeza con que le es dado el cogito, como sostiene Heidegger, lo que le impidió cuestionar la idea del yo, y de ahi, derivadamente la de ser. Como comenta J.L. Marion, "Descartes reduce el sum a cogito y el cogito al ego" 19 ¿Qué es o quién es yo?: un sujeto de actos entedido como lo presente permanente en el curso de sus estados internos o vivencias, y fundamental y esencialmente, el sujeto del acto de la cogiratio o conocimiento. De ahi que Descartes no pueda separar que es o existe y luego preguntarse qué es, aunque asi se exprese en algunas ocasiones, porque, en la evidencia originaria, se le ha dado inmediatamente la unidad del cogito y el sum. Se trata de una experiencia primordial y no de una deducción, como explicita en su Entretien avec Burman, " yo no presto atención más que aquello, de lo que tengo experiencia en mi mismo, a saber: je pense. donc je suis". ${ }^{20} \mathrm{Y}$ en otros pasajes, volviendo de nuevo sobre la cuestión, acentúa Descartes el valor interno la experiencia, en tanto que presupone un si mismo. Asi, por ejemplo, frente a los que opinan que para entender la tesis "cogito ergo smm", es preciso saber antes qué es pensar y existir, les replica en La Recherche de la verité, que tales nociones se sacan de la conciencia de si:

Alado que es imposible aprender estas cosas de otro modo que por si mismo y de ser persuadido de ello de otra manera que por su propia experiencia y por esta conciencia o por esle lestimonio interior que cada uno encuentra en él cuando se entrega a un examel cualquiera", 21

Is Meditation seconde en Onevres ef Lettres, op. cit., 277.

16 La l'olmmad de ctominio, pr. 483, Aguilar, Mladrid, 1947, pág 309.

17 Oetnres ef lestres, op. cit., 277.

18 Le conflit des interprétations, op. cit., 226-7.

19 Réduction el donation, op. cit., 133.

20 Oenres ef L'tres, op. cit., 1357.

21 Idein, 899 
Presencia a si o para si del cogito, entendida como auto-objetivación de si. De modo que tenerse presente en el acto es también, $y$ al mismo tiempo, es decir, en la experiencia mismil del acto, saberse en lo que real y verdaderamente es. Con ésto comenzaba el reinado de la Autropologia filosófica,

que es aquella interpretación del hombre -ironiza lleidegger- que en el fondo ya sabe lo que el hombre es, y por eso no puede preguntar nunca quién (Wer) sea él (Hz, 103, nota 10).

Ahora bien, la formulación heideggeriana de la pregunta por el sentido del ser exigía invertir el programa cartesiano. Muy probablemente, detrás de este planteaniento de Heidegger, esté la inspiración nietzscheana de volver del revés el idealismo desencarnado de la autoconciencia. No cogito ergo sum, sino cogito ergo est, 一dirá Nietzsche-, pienso luego hay ser. ${ }^{22}$ Puesto que hay pensamiento, la pregunta ontológica deberia preguntarse por lo que hace que haya pensamiento. No partir del ego cogito para atribuirle, en tanto que yo o subiectum un modo especifico de ser (substantia), sino a la inversa, preguntarse por el modo de ser que hace posible un ego cogitans. La declaración de Heidegger a este respecto en Sein und Zeit es bien precisa y no deja dudas de lasta qué punto entendia su propio programa como una inversión del cartesiano:

\begin{abstract}
Si como punto de partida de la analitiea existenciaria del Dasein hubiera de servir el "cogito sum", seria menester no sólo invertir (Umkehrung) su contenido, sino verificar este en una nueva forma fenoms:nico-ontológica (einer neuen ontologish-planomenalen Benwährung). La primera proposición seria entonces: "sum", y en este sentido "yo soy' en el mundo". En cuanto ente tal "soy" en la posibilidad de ser relativamente a diversas actividades (cogitationes) como modos del ser cabe los entes intramundanos. Descartes, en cumbio, dice: las cogirariones son ante los ojos (vorhanden), y en ellas es un ego también ante los ojos como res cogitans sin mundo (SZ, pr. 43). ${ }^{23}$
\end{abstract}

Según esta exprusa indicación, habría que entender la analítica existencial heideggeriana como el desmontaje ontológico/existencial de la tesis cartesiana del cogito, yendo por detrás de sus propios su-puestos, hacia una estructura o modo de ser, que pudiera dar cuenta y derrocar a la vez la primacía de la auto-conciencia. Se trata, pues, de una destrucción que socava desde dentro el fundamento establecido por Descartes, en tanto hace ver una condición de posibilidad subyacente a la cogitatio. ${ }^{24}$ Por otra parte, $i$ no será acaso esta "nueva verificación fenoménjco-ontológica", que aqui menciona Heidegger, lo propio de la "destrucción fenomenológica del cogito", que se anuncia en el parágrafo 18 de Ser y tiempo?. Ordinariamente suele pensarse que tal destrucción quedó pendiente en la obra de Heidegger, puesto que remite al segundo capitulo de la segunda parte de esta obra, que nunca apareció. Soy más bien de la opinión que esta tarea fué realizada al menos en parte, en el desarrollo de la analitica existencial, en cuanto ésta puede ser interpretada, ateniéndose a las propias declaraciones de Heidegger, como inversión del cartesianismo. Me inclino a pensar asi, puesto que en esta inversión se está poniendo en obra la nueva caracterización fenoménico-ontológica del Da-sein, que invalida el supuesto cartesiano. Pero por lo mismo cabria pensar, que en cuanto mera in-versión y profundización ontológico/existencial del cogito, el planteamiento de Sein und Zeit permanecia aún anclado en un

22 Veúse Jean Granier, Le problime de la vérité dans la philosophie de Nietasclse, Du Seuil, Paris, 1966. págs 336-343.

${ }^{23} \mathrm{SZ}, 211 ; \mathrm{ST}, 232$

24 En este sentido la destrucción fenomenológié emprendida por Heidegger difiere esencialmente de la destrucción ontológica, que el propio Descartes ha hecho, según Jen-Luc Marion, de su propia tesis del cogito (Sur le prisme metaphysique de Descartes, op. cit., 161-3. 172-3). 
fondo residual de transcendentalismo. De ahi que, a mi juicio, los posteriores desarrollos de la critica heideggeriana a Descartes, ya sea en Holnvege o en Nietssche // no sólo completan esta destrucción, sino que vienen a salvar a la nueva idea de trascendencia (Tranzendens) lograda frente al cartesianismo en Sein und Zeil, de todo posible contagio trascendentalista.

\section{Trascendencia versus intencionalidad}

Ya en la primera presentación de la estructura ontológica del Da-sein, desde los primeros parágrafos de Ser y tiempo (pr. 13), se advierte que la analitica existencial es in nuce una deconstrucción del cartesianismo. Lo que Heidegger pone en entredicho desde primera hora es la primacia de la cogitatio, que habia servido de punto de partida a la metafisica del cogi1o. Dicho en otros términos, que el problema del conocimiento no puede ser fenomenológicamente directivo en el planteamiento de la cuestión ontológica, pues no es un fenómeno primario y fundamental desde el punto de vista de la ex-sistencia. Podria alegarse que esto ya lo sabía Descartes, y el mismo Husserl, y de ahi que el fenómeno de la cogitatio sólo sea accesible tras la desconexión por la duda metódica de la conciencia natural, pero el problema está en saber si este nuevo ámbito de la conciencia pura, dado en la inmanencia del yo, no sólo desfigura a la conciencia fungiente o ejecutiva del mundo sino que hace imposible a radice el propio conocimiento. La cogitatio, tal como queda una vez puesta entre paréntesis la tesis (fe o convicción) del mundo, por utilizar una expresión fenomenológica, no es más que una pura correlación intencional entre el cogito y el cogitatum, el acto subjetivo y su contenido objetivo, o dicho en términos luusserlianos, la noesis y el noema. La actitud es aqui puramente teorética o contemplativa, pues ha desconectado todos los intereses prácticos vitales, que estaban vigentes en la tesis natural, y, por tanto, se limita tan sólo a ver o tener presentes, esto es, "ob-jetivamente", los términos correspondientes a las vivencias intencionales. La intencionalidad, esto es, la capacidad de pro-ponerse ob-jetos, haciéndoselos presentes en su ser es la determinación misma de la cogitatio. Estos son las ideas, entendidas ahora como mero id quod cognoscitur, es decir, lo primero que inmediata y propiamente constituye el término de la intentio cognoscitiva, por tanto, el objeto presente al acto mental, y de ahi derivadamente la interpretación cartesiana de su modo de ser correspondiente como sustancii. El planteamiento epistemológico cartesiano seria, pues, el responsable de tal encubrimiento, y no sólo en lo que respecta al sujeto (ego) del cogito sino a sus objetos o cogitata. Como precisa el propio J.L. Marion, "mientras más invade la certidumbre epistémica otros sectores cada vez más extensos del ente volviéndolos homogéneos como otros tantos cogitata, tanto mís el conjunto del ente traiciona la indeteminación básica en que le deja el olvido de toda interrogación sobe aquello que, en cada caso, quiere decir ser para cada ente, para cada sector del ente". ${ }^{25}$ De ahí que, a la primera falta del planteamiento cartesiano, relativa a la indeterminación del ser del ego cogito, haya que aradir una segunda, que concierne al fenómeno del mundo. En suma, -concluye J.L. Marion- "la interpretación del ser en general como permanencia subsistente bajo-la-mano (l'orhandenheit) no sólo falla el sentido del ser del ego dejando el sum indeterminado como tal en el; falla también y ante todo el sentido del ser del ente intra-mundano, del que pretende, por tanto, asegurar el perfecto conociniento", ${ }^{26}$ $y$, por tanto, del fenómeno del mundo interpretado únticamen te como suma de lo subsistente presente.

25 Reduction ef donation, op. cit., 133.

20 Idem, 137. 
Estos contenidos objetuales se dan, por otra parte, en la inmanencia de la conciencia, o en su esfera interior, vuelta ésta hacia si misma, y suspendida su relerencia existencial al mundo. Muy taxativamente precisa en este sentido Descartes que

el espiritu cuando piensa se vuelve en cierta medida hacia si mismo, y considera algunas de las ideas que él tiene en si; pero cuando imagina se torma hacia el cuerpo y considera alguna cosa conforma a la idea que él ha formado de si mismo o que el ha recibido por los sentidos (Medit. 6). ${ }^{27}$

Cree Descates haberse asegurado asi un ámbito originario, expurgado de todo relativismo, y donde ya no pueda morder el piquete de la duda. Ya se ha mostrado el camino en que Descartes ha establecido el modo de ser sustancial de este sujeto intencional puro, que transciende la experiencia empirica, pero que, sin embargo, no puede transcender-se de sí mismo. Pero justamente los problemas más intrincados del conocimiento aparecen — señala Heidegger- cuando se quiere hacer valer este ámbito como el fundamental:

Como quiera que se interprete esta esfera intema, sollo con que se plantee la cuestión de cómo salga de ella el conocimiento y logre una "trascendencia" (Transzenden:), salu a la vista que se encuentra problemático el conocimiento sin liaber aclarado antes cómo sea y qué sea este conocimiento que propone tales enigmas (SZ, pr. 13). ${ }^{28}$

La idea de trascendencia es aqui decisiva. Porque si algo signtica el fenómeno primario del conocimiento, con anterioridad a toda interpretación, es justamente lo que se recoge en la fe o convicción natural, el previo estar con cosas y ante cosas en el contexto de un mundo. Sin trascendencia, en el sentido expreso de apertura a lo otro de si, o si se quiere de estar-ya-enrealidad, no es posible dar un sentido plausible al problema del conocimiento. Conocer es una conducta teorética o reflexiva, que se ejerce sobre cosas, teniéndolas presentes en su ser, pero si se ha desconectado el ámbito originario del darse mismo de las cosas, en cuanto tales cosas, a la conciencia natural, ya no puede haber garantía de que el nuevo mundo, puramente objetivo, sea conforme al mundo real. Se diria que la idea básica de objetividad, como el producto directo e inmediato de una intención concipiente, ${ }^{29}$ y de verdad, como evidencia o certeza de lo que clara y distintamente se ve, propias de este nuevo ámbito de la conciencia pura, ya mada tienen que ver en principio con el orden de lo en sí real. Sólo a través de la mediación onto-teológica del ser necesario, tendrian que ser restablecidas en su conexión con la realidad. Más radical, pues, que la intencionalidad objetivante es la troscendencia en cuanto movimiento cxis. tencial del trascenderse del Da-sein a la posibilidad de su ser y con ello, a lo abierto de un mundo. ${ }^{30}$ Lo primario es, pues, para Heidegger, este previo estar-en-el-mundo, que es lo mentado con el fenómeno del $\mathrm{Da}$-sein. Si se arguyera que de este modo se recae en una actitud inge-

27 Oenres et lentes, op. cit., 319.

$28 \mathrm{SZ}, 60-61, \mathrm{ST}, 73$.

29 Este es, a mi juicio, el sentido de la intuición intelectual cartesiana como pura mentis inspectio, "la concepión de un espíritu puro y atento, concepción tan fácil y tan distinta que no quede ninguna duda sobre lo que cornprendernos o, lo que es lo mismo, la concepción firme de un espintu puro y atento, que nace de la sola luz de la razón:" (Reglas, III, en Oenres el leures, op. cit., 43-4). Sobre las Regulae ad directionem ingenii da Descartes, puede verse el excelente estudio monográfico de J.L. Marion, Sur l'ontologie grise de Descartes, (Vrin. Paris, 1975) y la muy documentada Introducción de Juan Manusl Navarro a su traducción de las mismas (Reglas para la dirección del espiriru, Alianza Editorial, Madrid. 1989. págs 7.57). (1928). 
nua y dogmática, en la que se dan por resueltos todos los problemas, cabria replicar con Hegel que una critica del conocimiento, si no quiere embarcarse en una inquisición infinita, y a la postre, externa sobre el conocer del conocer, tiene que dar por supuesto el fenómeno originario del conocimiento y moverse ya de antemano en él. Lo que no impide que este movimiento en el contenido o del contenido, tenga un carácter autocrítico $\longrightarrow$ dialéclico, diria Hegel-, como una transformación de la propia experiencia del mundo. El supuesto epistemológico de que la crítica requiera una descontextualización y hasta aislamiento metodológico del ser-en-elmundo conduce al vaciamiento ontológico del propio fenómeno que pretende analizar. La crítica tiene que darse ya de antemano en realidad, o no logra nunca engranar con ella. De modo que lo que hay que aclarar y justificar, según Heidegger, es propiamente la actitud teoréticoreflexiva. Pero ésta no surge por una desconexión metódica, tan artificial como la propia duda cartesiana, sino de la desconexión práctica, ejecutiva, que acontece espontánemete en la conciencia natural, cuando resulta "deficitario" (Defizienz) su modo de habérselas con el mundo (zu tum haben mit der Ilelt), y necesita, por tanto, reparar en y demorarse cabu lo inmediato, poniéndolo a la vista (SZ, pr. 13). ${ }^{31}$ Esta desconexión no invalida, pues, la tesis del mundo, antes bien la supone y la ejercita, sólo que por modo reflexivo. Como advierte Heidegger,

en el mero saber de una relación de ser de los entes, en el sólo representársela, en el pensar simplemente en ella, no soy menos cabe los entes ahi fuera en el mundo, que en un acto de aprehensión original (SZ,pr. 13). ${ }^{32}$

Por debajo, pues, de la conciencia con sus cogitationes, ésto es, en un lugar, a la vez, más primario y fundamental, esto es, en el lugar $(d a)$ de la cuestión del ser (Sinn des Seins), está la estruclura ontológico/existencial del "ser-en". Es a ésta a la que Ilama Heidegger cuidado (Sorge), con un término pregnante, que recoge la intencionalidad práctico/vital y fungiente del Da-sein. Cuidar como hacerse cargo, habérselas con, sencillamente, habitar el mundo:

Ser (Sein) como infinitivo del yo soy (ich bin), es decir, comprendido como existenciario, significa habitar cabe... (SZ,pr. 12) ${ }^{33}$

Resulta evidente la referencia implicita de este "yo soy" (ich bin) del cuidado al ego sum cartesiano de la cogitatio. También para Descartes vale que el sentido del ser (infinitivo) está en el sum, como un acto, del que sólo un yo (en primera persona) ${ }^{34}$ puede dar fe. Pero este acto ya no es primariamente "conciencia de...", sino ex-sistencia (Existenz), en cuanto hacer por ser y tener, por tanto, que habérselas con el mundo. La apertura a la realidad se debe al propio estarabierto el ex-sistente a su ser. Incluso, la misma elección del ténnino Da-sein frente a otros acuinados en la tradición filosófica como alma, conciencia, yo, espíritu, quería evitar a toda costa interpretaciones históricas, que se prestaban a contagios cartesianos, y atenerse al Urfaktum de

\footnotetext{
$31 \mathrm{SZ}, 61$, y ST, 74.

$32 \mathrm{SZ}, 62 ; \mathrm{ST}, 75$.

3) $\mathrm{SZ}, 54 ; \mathrm{ST}, 67$.

34 Como precisa muy finamente Jean-Luc Marion, "à la question sur l'etre de l'étant, Descartes répond: primus stm, ou bien: ego sum est la premiére connaisance, donc la plus certaine; bref la manière d'etre de l'b́tant se definit - sum, etre conformément à l'ego" (Sir le prsime metaphisique de Descartes, op. cit., 78). Bernard Williams menciona a este propósito el carácter realizativo, "pues el acto mismo de pensar la proposición la que la hace verdadera" (Descartes. El prọtecto de la imestigación pura, Cúledra, Madrid, 1978, pág 95-102).
} 
la ex-sistencia, que es más primario y fundamental que el cogito. El Da-sein es fundamentalmente una relación, no al mundo interior de las cogitationes, ni siquiera al mundo exturior de las cosas, -interior y exterior son expresiones de inspiración cartesiana-, sino sencillamente al ser (Bezug zu sein). ${ }^{35}$ En la propia tarea de hacer-por-ser, en ser para si constitutivamente problema, se encierra la posibilidad de la pregunta ontológica por el sentido del ser. La omisión de esta pregunta es el origen del doble encubrimiento cartesiano. Tal como ha seitalado certeramente el propio J.L. Marion, "revela de inmediato que a Descartes le ha faltado afrontar la diferecia entre ente y ser, la única que la luabria permitido fijar ontológicmente la distinción entre entes o sustancias. La convergencia entre los dos fallas - del sentido del ser del ego, y del sentido del ser del ente intramundano- resulta finalmente del esquivamiento originatario ante la diferencia ontológica". 36

A partir de este cncubrimiento u olvido de la cuestión del ser, es posible entender la analitica existencial heideggeiaiana como una destrucción del ego cogito, o como su estricta inversión. ${ }^{37}$ De aqui surgen las diferencias radicales que, a la vez, asemejan y distancian, paradójicamente, ${ }^{38}$ a Heidegger de la posición cartesiana del cogito. Como se acaba de mostrar, el "ser-en" es pues el Ur-faktum inesquivable e indisimulable, intranscendible, donde está el secreto de toda trascendencia. La contraposición en este punto a Descartes salta a la vista: en vez de la apodicticidad del ego cogito = ego sum, como el lugar indubitable de la autopresencia en si para si, señala Heidegger la facticidad (Fakli=tät), el efectivo existir como un faktum radical, por detrás del cual ya no se puede ir. La censura que este punto dirige Heidegger al trascendentalismo cartesiano/husserliano es de una extrema contundencia:

Las ideas de un yo puro y de una conciencia general están tan lejos de encerrar lo apriori de la real subjetividad, que pasan por al to o ni siquiera ven los caracteres ontologicos de la facticidad y de la constitución del ser del Dasein (SZ, pr. 44). ${ }^{39}$

¿De qué se trata en la facticidad, como para merecer tan severo reproche?

Se podria afirmar que la facticidad es la contrafigura o contrafactura de la auto-conciencia pura. No es casual que en la idea de facticidad haga valer Heidegger la dimensión del destino (Geschick), es decir, de lo que no cabe dar razón ni apropiárselo en un acto de libre disposición de sí. Está aqui en juego una conciencia que no es soberana, sino que forzosamente se comprende como "siendo su destino estar vinculado con el ser de los entes que le hacen frente dentro del mundo" (SZ, pr. 12). ${ }^{40}$ La facticidad es asi el limite intrinseco, infranqueable e inexorable, que se opone a la voluntad de autofundación del yo transcendental de estar presente a sí mismo en la raiz de su acto. El limite consiste en no poder no. El Da-sein no puede

\footnotetext{
35 De ahi que para caracterizarlo, acune Heidegger una expresión nueva, no contaminada por ningua categoria antropolठgica clásica, -Daseir-, "en cuanto pura expresión da ser" (SZ,12;ST,22)

36 Reduction et donation, op. cit., , 139.

37 ldem. 147.

38 En cuanto el Dasein es la contra-figura o imagen inveritda del cogiro, es posible plantear semejanzas estruc. turalmente hablando entre ellos. J.L. Marion ha desarrollado algunas de estas convegencias, —en la finitud, la yoidad y el ser mortal-. lo que le pennite concluir, con entera consecuencia, que "el ego aparece al Dasein como un desfallecimiento, pero ante todo como su propio desfallecimiento, y por consiguiente, sobre todo, como un $\mathrm{k}^{\mathrm{e}}$ ligro, cuya fascinación impone sus normas y a la que es preciso resistirse mejor de lo que lo liciera Husserl" (Idem, i55). Que el cogito suponga un desfallecimiento del Da-sein es otro modo de reconocer con Heidegger que en el cogilo cartesiano se interpreta el yo a partir de la forma del ente intramudano de que se ocupa.

$39 \mathrm{SZ}, 229 ; \mathrm{ST}, 250-1)$

$40 \mathrm{SZ}, 56 ; \mathrm{ST}, 68$.
} 
dejar de ser lo que ya es, no puede no ser un existente yecto ya-en-ser y pro-yectado constitutivamente hacia la muerte, no puede no pro-venir de un pasado y dejar de ad-verir constantemente a un futuro, no puede contenerse en el presente absoluto de una presencia omnimoda, no puede, en suma, de-clinar su finitud. Su presente es una figura de tiempo y cuidado. Lo que deniega la facticidad es precisamente la fundamentalidad del cogito en cuanto sede o lugar originario de la verdad. Erige así, frente a la necesidad epistemológica cartesiana de la prima veritas - la coincidencia o identidad del pensamieto y el ser-, esta otra, terca e inevitable, necesidad existencial de la no-coincidencia ni con-sigo mismo ni con el ser. ${ }^{4 !} Y$ esta necesidad, en cuanto inevitable e infundamentable, es ahora la caracteristica señalada con que se impone, como punto de partida, el lugar abierto como ahi (da) del ser.

Ahora bien, si el sum del cuidado es el sum de la ex-sistencia como trascendencia, -trascendida en cuanto yecta en un orden no fundado por ella y trascendiéndost hacia la posibilidad de lo que ha de ser-, el ego del sum ya no puede ser pensado en los términos de un sujeto sustancial. La interpretación del yo como sujeto es la propia de un principio autárquico, que es suyo en cuanto se pertenece radicalmente a sí mismo, en la raíz de su actividad. Su ser sustancial expresa ontológicamente esta autarquia de la experiencia del stijeto. El yo, en cambio, de la ex-sistencia es suyo, justamente en el sentido opuesto, en cuanto le va su ser. "El ser que le va a este ente en su ser es, en cada caso, mio" (SZ pr. 9) ${ }^{42}$-precisa Heidegger-; está se-ñalado por un yo, que se siente concernido por irle en su existencia su ser. No es suyo en la soberana dis-posición de si, sino en la precaria exposición de quien hace por ser. En suma, no consiste en su autopresencia esencial sino que exsiste en su posibilidad. Pero esto quiere decir, que más que sub-iecto de auto-posesión, es el Da-sein pro-yecto de auto-constitución. Estos dos caracteres originarios del Da-sein, - -la preeminencia de la existencia sobre la esencia y el ser, en casa mio"-, rechazan frontalmente el concepto de sustancialidad, esto es, de un ser clauso en su esencia y entendido como sujeto ontologico último:

Este sujeto es el mismo en medio de sus múltiples alteraciones y tiene por tanto el carácter del s! mismo. Aunque se rechace la sustancia psiquica, igual que el ser cosa de la conciencia y el ser objeto de la persona, ontológicamente no se pasa de sentar algo cuyo ser conserva expresamente o no el sentido del ser ante los ojos. (lorhandenheis) La sustancalidad es el hilo conductor ontológico para llegar a la definición del ente con el cual se responde a la cuestión del quiśn $(\mathrm{SZ}, \mathrm{pr} .25)^{43}$

¿Qué más natural, esto es, más habitual y obvio, que atenerse a este dato indubitable de la conciencia de "si mismo"?. Y, sin embargo, este no deja de ser un pre-juicio cartesiano, vinculado a la primacia intelectual de la conciencia reflexiva. Para Descartes, el sí mismo (soimeme) estriba en esta coincidencia o identilicación en el ego, del cogito y el sum, de modo que en su auto-presencia a si, coincide su saber si y su ser. El "si mismo" es la expresión de esta constante adhesión del sujeto a sus actos, liaciéndolos suyos en cuanto le están presentes de modo inmediato en la interioridad sin fisuras ni distancias de su autoconciencia. Pero realmente, ¿se sabe y se tiene a si mismo el yo en una autopresencia constante? ¿Es el "si mismo" un

41 Se impone, pese a las diferencias de planteamiento, una mención a Montaigne, quien, en el comienzo inismo de la modemidad, sostuvo, a diferencia de Descartes, la imposibilidad para el yo de resolverse de un modo delinitivo (Essais, en Oeanres complètes, Gallimard, Paris, 1962, págs 782 y 586).

$42 \mathrm{SZ}, 42 ; \mathrm{ST}, 54$.

$43 \mathrm{SZ}, 114 ; \mathrm{ST}, 130$ ). 
hecho inmediato de auto-conceincia, o más bien una conquista existencial en la apropiación ejecutiva de la fáctica posibilidad de ser?. Heidegger, al modo de Nietzsche, levanta una sospecha contra esta al parecer indubitable presencia a si:

Quizh, el Da-sein diga, siempre que inmediatamente "dice de sí mismo", soy yo, pero a la postre lo diga mís alto que nunca justo cuando no sea este ente (SZ, pr. 25) ${ }^{4+}$

Descartes supone, por lo demás, que este "si mismo" es un yo aislado de todo lo deınás, firme diamantinamente en la tautologia de su constante identidad, en la soledad de su autoconciencia. Pero si no hay yo sin mundo, el yo sólo puede lograr su "si mismo", concreta y fácticamente, en el seno de su propia tarea de ser. Puesto que el Da-sein está existencialmente abierto al mundo, no puede encontrarse a "si mismo", recluyéndose en la soledad de su autoconciencia, sino en lo abierto del mundo:

El Dasein se encuentra a si mismo inınediatamente en lo que hace,usa, espera, evita —en lo "a la mano" de lo que se cura inmediatamente en el mundo circurdante (SZ pr. 26). 45

Pero con este viraje desde el yo tautológico de la auto-conciencia, al yo ejecutivo de la existencia, de-clinado temporalmente de si en su origen y proyectado ad-viniendo hacia su posibilidad, la cuestión del quien no admite una respuesta categórica y formal, "entonces la cuestón del quien sólo puede responderse verificando fenoménicamente una determinada forma del ser del Dasein" (SZ,117; ST, 133). El yo, que ex-sistiendo es en cada caso suyo porque le va su ser, no es por eso existencialmente "si mismo", si no se apropia por si y desde si de su fảctica posibildad de ser. Ser "si mismo" o no ser "si mismo", ganarse en su posibilidad propia o perderse en ella, son dos alternativas existencialmente abiertas, es decir, en curso temporal, e igualmente fundadas en el ser ontológico/fenomenológicamente "mío" del yo, en cuanto tiene en juego su ser. Desde Aristóteles, es muy clara la convicción de que el tiempo conmueve esta figura de ser macizo y enterizo, de ser presente/permanente a través de la diversidad de sus estados y vivencias; el tiempo que destruye la sustancia como permanencia de un núcleo constante de ser. Sólo conteniéndose en un presente sin declinación puede el ente salvar su identidad sustancial. De ahi que la sustancialidad pertenezca propiamente a la forma, y sobre todo, a aquella forma pura, presente a si misma en la radicalidad de su acto: la noesis noeseos. Pcro si el tiempo es el destino del existente, $y$ si este, en cuanto figura de tiempo, se le oculta su origen y no puede sustraerse a su referencia constitutiva a la muerte (sein zum Tode), su "sí mismo" no podrá ser nunca una autoposesión asegurada, sino una modalidad concreta, siempre en precario, de su forma de ser. Se comprende asi que el ego sum de la existencia, en cuanto temporalmente abierto, es propiamente un ser mortal. Yo soy no afirma entonces otra cosa que yo soy mortal. Sólo quien no conoce el tiempo y la muerte, o quien se la escamotea existencialmente, estriba o cree estribar en un "si mismo" formalmente asegurado y estable.46 $\mathrm{El}$ mortal, por el contrario, sólo gana su "sí mismo" en la fidelidad a su propia condición, en resolución ex-sistencial frente a los riesgos de la autoocultación y el ennascaramiento.

${ }^{44}$ SZ,115: ST,131.

45 SZ,119; ST, 135 .

46 Por éso no puedo estar de acuerdo con J.L. Marion en las convergencias que plantea entre el ego cartesiano y el Dasein (Cfr Réduction et donation, op. cit., 147-151), pues ni en la finitud ni en la yoidad pueden tomarse. estrictanente hablando, como estructuras equiparables 